\title{
The Interplay of Site and Construction Systems Decisions for Complex Urban Infrastructures
}

\author{
Bryan R. MOSER ${ }^{1}$, Cassie BELLEW, Adele CADARIO and Roland de FILIPPI \\ Massachusetts Institute of Technology, USA
}

\begin{abstract}
For development of urban infrastructures, such as smart cities and reconstruction of existing energy, transit, and population hubs, critical decisions are made during the early shaping of these projects. Many stakeholders are involved, including non-experts, some of whom may be impacted but not beneficiaries of the investments. We refer to a subset of the decisions as "systems architectural decisions" - not because these decisions relate to the architecture professions - but because they are meaningful, impactful, and sensitive decisions which drive many of the downstream choices and emergent impacts of the project. Often these early decisions are based predominantly on the site itself and its operation. In this paper we explore systems models for stakeholders of complex, urban infrastructures including architectural decisions related to implementation, such as phasing, construction, and project organization. In research underway on a transit hub project in Tokyo, Japan, we explore how inclusion of these decisions as part of a broader morphological matrix of site decisions influences the tradespace of emergent outcomes. In this way we seek to bring strategic discussion of construction options into the early framing of urban infrastructure projects.
\end{abstract}

Keywords. Construction Planning, System Architecture, Smart City, Stakeholder Value Network, Morphological Matrix

\section{Introduction}

Global construction output is forecast to rise to US\$12.9 trillion in 2022, up from US\$10.9 trillion in 2017 [1]. Only 11\% of construction industry professionals consider jobsites to be very efficient [2]. Large projects across asset classes typically result in $20 \%$ schedule overruns, and up to $80 \%$ budget overruns [3]. The building and construction sectors have the largest share of energy consumed and generated emissions. Building construction and operations accounted for $36 \%$ of global final energy use and approximately $40 \%$ of energy-related carbon dioxide emissions in 2017 [1].

An program is a project so large that its major components are projects in their own right [4]. Megaprojects are large-scale, complex ventures that typically cost a billion dollars or more, take many years to develop and build, involve multiple public and private stakeholders, are transformational, and impact millions of people. Megaprojects are inherently risky due to long planning horizons and complex interfaces. 9 out of 10 megaprojects have cost overruns typically up to $50 \%$, with extreme cases such as the

\footnotetext{
${ }^{1}$ Corresponding Author, Mail: bry@mit.edu.
} 
Channel Tunnel (80\%), Boston's Big Dig (220\%), and the Sydney Opera House $(1,400 \%)[5]$.

\section{Related Research}

Previous research suggests that the construction industry is characterized by particular complexity owing to industry specific uncertainties and interdependencies, and inefficiency of operations [6]. Researchers have also a continuous increase in complexity of construction projects. Construction production planning is a paramount preoccupation of contractors and the process is rapidly increasing in difficulty [7]. Further, complexity in construction originates from a number of sources: resources employed, the environment in which construction takes place, the level of technical capability, and the number and interaction of different parts of the workflow.

Gidado distinguished between two categories of complexity: the first, related to 'uncertainty' which deals with the 'components that are inherent in the operation of individual tasks and originate from the resources employed or the environment', and the second, stemming from 'interdependence' among tasks, which represents those sources of complexity that 'originate from bringing difference parts together to form a workflow' [7]. Expanding on interdependence, Gidado identified three factors: (1) the number of technologies and the interdependence among them; (2) the rigidity of sequence between the various main operations; and (3) the overlap of stages or elements of construction. This definition is consistent with the work by Sinha and de Weck in Engineering Systems which describes the elemental, pairwise, and topological contributors to complexity.[8]

The unique conditions of each site significantly drives the construction process, and construction firms apply an appropriate method to execute the project [9]. Decision making, planning, and management are typically multi-actor processes, involving multiple stakeholders, public and private, often with conflicting interests [5]. Multilayered sub-contractors cannot see the whole project and optimize their behavior. This task-level optimization sometimes sacrifices benefits for the total project [9].

\section{Related Case: Paris Rive gauche}

A recent urban infrastructure case with similarity to the Tokyo Takanawa case later in this paper is explored here for context.

"Paris Rive gauche" is an urban development currently going on in Paris, started in 1991, when the City of Paris approved of the area's development project ${ }^{2}$ and created the development area $^{3}$. This operation is singular in Paris first for its scale: 130 hectares, and also for the chosen deep imbrication with transportation infrastructures: 26 of its 130 hectares are built above railroads ${ }^{4}$, creating a "layer of city" above the existing layer of railroads.

${ }^{2}$ PAZ: Plan d'aménagement de la zone

3 ZAC: Zone d'aménagement concertée, initially named "Seine Rive Gauche"

${ }^{4}$ Railroad from the Austerlitz train station, that operates regional, and national trains to Orléans and the South of France. 
This ambitious operation's development is today mostly delivered, with some parts still under construction, especially on the east edge of Paris. The operation overall offers 25.8 M SF of construction (housing, offices, retail, public equipment) ${ }^{5}$, and $1 \mathrm{M} \mathrm{SF}$ of public green spaces. Paris Rive Gauche has been shaped by strong initial decisions, that have initiated the way the operation was able to evolve and mute over the long time of its construction:

- $\quad$ The large scale of the operation, conceived as one ambitious area (instead of several smaller sized neighborhoods), was a challenge in term of vision (unicity of scale for the overall project) and yet required phasing (multiplicity of times for construction).

- One early stage fundamental decision was to define, at the whole area scale, a primary grid of public spaces, strongly articulated with the Avenue de France, a line (or backbone) that extends for $2.3 \mathrm{~km}$ all across the area. The secondary grid of public spaces was then purposively not defined at first, to enable advanced studies to elaborate specific urban design per sub-areas over time ${ }^{6}$.

- This articulation in space resonated with an articulation in time: imagined in the late 80 's, started in the 90's, and implemented over since, the operation has been through different economic contexts for real estate ${ }^{7}$. The decomposition by neighborhood, with different timing of construction and sells, yet with an overall economic balance over the whole area, introduced different prioritization over time.

- Political expectations also had time to evolve: the city of Paris updated the operation objectives in 1997, 2000 and $2009^{8}$, introducing new concerns (for example, environmental objectives) and updating the balance of spaces in the operation, and the overall schedule.

Initially planned to be completed by the year 2000, the area has been under construction, piece by piece, for almost 30 years. Initial decisions, and changes that have occurred over time driven by new circumstances or expectations, have impacted the construction outputs (timing, costs, methods). Could it be possible to create different set of circumstances, expectations, and decisions, in order to evaluate and to compare different possible scenarios - and improve available information at the decision time?

A stakeholder value network [10] for the development of Paris Rive gauche is shown below in Figure 1. In addition to local residents, businesses, transportation and government agencies, when viewing the site as a construction project over many years the Contractors, Real Estate Developers, and Utilities become more topologically significant in the network. Given that the construction and development has been underway for 30 years, these stakeholders and the flows amongst them are significant to the life and performance of the site.

\footnotetext{
${ }^{5}$ Decomposed as : $7 \mathrm{M} \mathrm{SF}$ of housing (7 500 units), $8 \mathrm{M} \mathrm{SF}$ of offices, $4 \mathrm{M} \mathrm{SF}$ of retail and activities, $7 \mathrm{MSF}$ of public equipment (university, national library, local equipment)

${ }^{6}$ Sub-area: Austerlitz, Tolbiac, Masséna Université, MAsséna Chevaleret, and in a further time horizon Bruneseau

${ }^{7}$ In Paris: boom in the real estate industry, during all the second half of the 1980's. Crisis in 1991, followed by almost a decade of down real estate economy.

${ }^{8} 1997$ : operation « declared of public-benefit » (DUP), 2000: decision to build an University on the area, 2009: Public consultation for the zoning revision in the Bruneseau Nord area.
} 


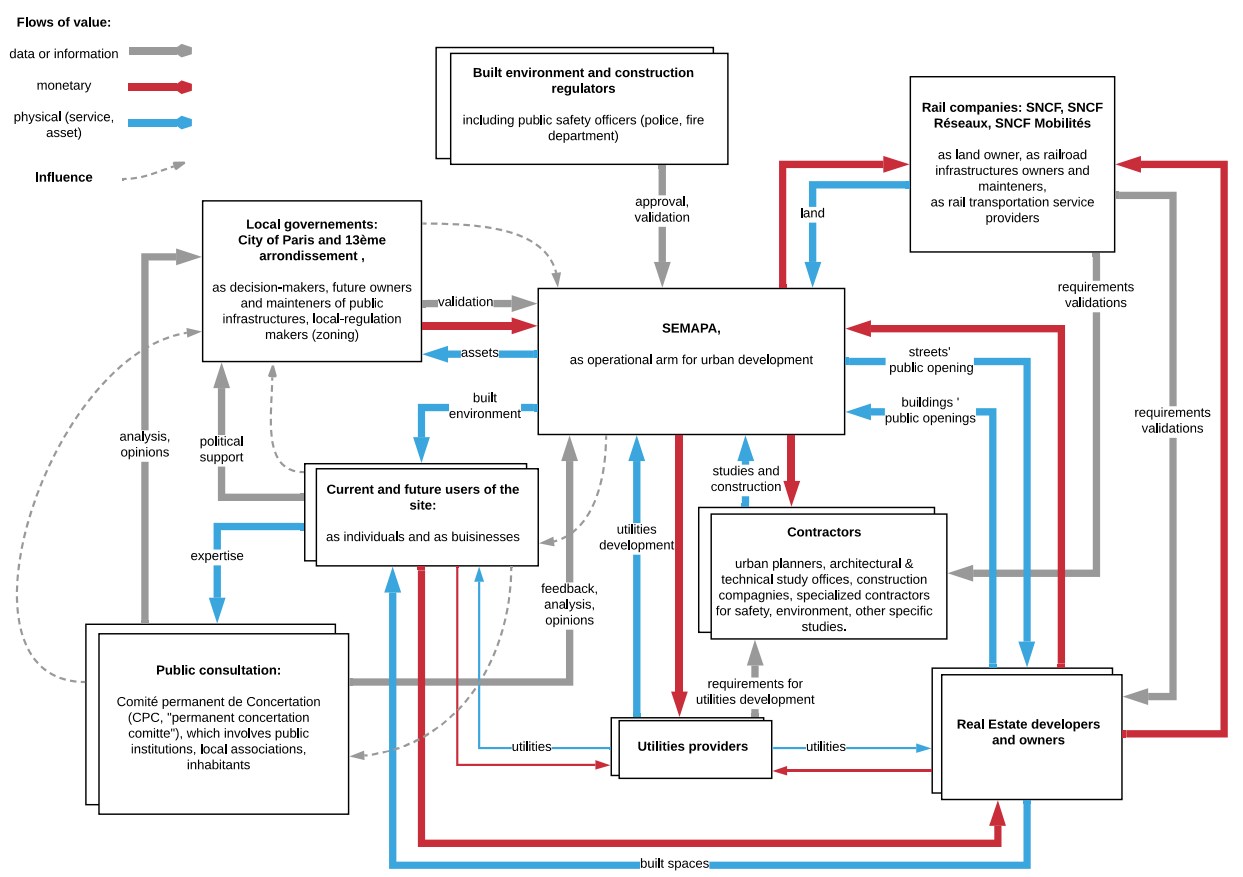

Figure 1. Stakeholders value network - Paris Rive Gauche operation.

\section{Research Approach}

Our ongoing research has focused on the treatment of building sites and infrastructures as a complex system of systems.[11] This approach, originally applied to complex systems in aerospace, has been extended to consider various infrastructure systems, ranging in scale from building to region (and even the solar system).[12] The approach leverages a class of systems modeling, characterizing a site as system with boundaries, value producing functions, interfaces, objects, and instruments rather than the traditional emphasis on aspects of physical form.

The performance of a complex system is driven most significantly by a subset of decisions made at the outset, referred to as "architectural decisions". The challenge in representing sites as systems is to know which decisions amongst these are important, sensitive and impactful ones, and which other decisions are less significant, able to be made downstream, less impactful or naturally follow from the architectural decisions[13].

A Systems Architecture is a set of selected and integrated options - one for each decision -- that together define a particular (feasible) design of the complex system.[14] During system modeling, the architectural decisions can be shown as a morphological matrix, with a key decision for each row, and major options for each decision shown across the row (see Figure 2 below). System architects select amongst the options in combination, generating a single scenario, or "architecture", one for each row. 


\begin{tabular}{|c|c|c|c|}
\hline Decision & \multicolumn{3}{|c|}{ Option } \\
\hline Decision 1 & Option 1 & Option 2 & Option 3 \\
\hline Decision 2 & Option A & Option B & (N/A) \\
\hline Decision 3 & Option i & Option ii & Option iii \\
\hline
\end{tabular}

Figure 2. Systems Architecture as Shown in a Morphological Matrix [15].

This systems modeling approach has been recently applied to infrastructure projects, including desalination and energy infrastructure in the Middle East and shipping infrastructure transition to natural gas for the reduction of emissions.[16] With instrumentation of systems models and interactive visualization, our research observes the exploration, interaction, and decisions by stakeholder teams during the early planning and design process.[17], [18]

For each architecture - a set of decisions in combination - the performance of the system is enumerated and evaluated. Enumeration is the generation of a set of meaningful architectures, including an approach to do so smartly given the easily explosive number of decision and option combinations. It may be likely that many combinations are not meaningful, therefore enumeration includes the consideration of constraints on option combinations. Evaluation, for those architectures that are enumerated, is the calculation of performance of the system. While some performance characteristics can be estimated in absolute terms, often (for the purposes of architectural selection) the evaluation is calculated to allow an ordinal and relative estimate for each performance dimension (or “'ility").

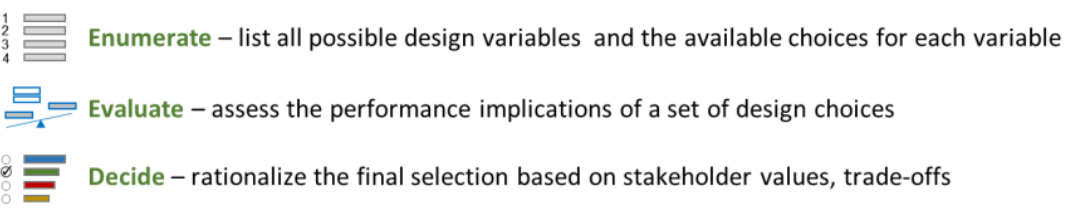

Figure 3. Architectures are enumerated and evaluated so that teams can decide on solutions.

In this paper we turn to systems architecture modeling for sites and infrastructure, then specifically to consideration of construction phase of these systems.

\subsection{Transit Hubs, Smart Cities, and Transportation Networks as a System of Systems}

This section introduces a generalized modeling approach under development for treatment of urban environments as systems. The case explored for this research paper is the development of a multi-mode transit hub tied to a "smart city" neighborhood and connected to the regional transportation network.

When viewing transportation performance at the macro-scale in a network, a classic representation from operations research and transportation may be used. In these models the activity at the local level is abstracted away, with an emphasis on the flow and topology of the network.

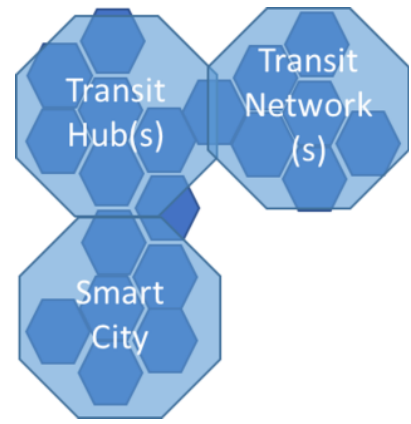

Figure 4. System elements capture phenomena at urban, hub \& network layers. 
Similarly, if viewing the system predominantly as a smart city, then the buildings, their spaces, and data regarding the experience and functionality of services in these spaces may be the emphasis of representation. The transit hub connecting these two transportation network and smart city -- stands in the middle (see Figure 4). The transit hub may be distributed and integrated into the city intentionally to increase pedestrian traffic across the site and for other reasons. Consider Penn Station in NYC, where retail and transportation are integrated into the warren of tunnels to access the rail platforms. Any airport with a mid-field terminal also demonstrates this splitting of hub functions into multiple separate hubs. A modeling approach is needed that captures aspects of transportation at the network level and yet also phenomena and performance within and urban spaces.

\subsection{Model of Sites with Spaces as a System}

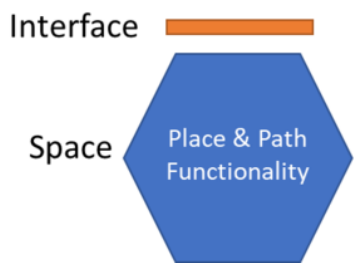

Figure 5. Basic Elements: Spaces \& Interfaces.

The basic model for a site model used here is a space, which contains both aspects of place and path. The "placiness" of a space represents the functions of, and for, those people who are in the space; residential, commercial, retail, health etc. The detail physical layout of the functions within the space are not modeled; if needed, one would choose to further decompose the space into smaller sub-spaces.

The "pathiness" indicates the potentially feasible mobility of entities in the space, including the density, capacity, and rules for entering, staying, and departing the space. Modes are the instruments by which people and/or goods are moved; e.g. walking, cycling, elevator, car, train etc. Paths within a space are evident at the interfaces which indicate connection of one space to another. Rules of the space in conjunction with the related interfaces may indicate directionality, latency, and modes feasible across the interfaces. However, the detailed position of paths within the space are not modeled.

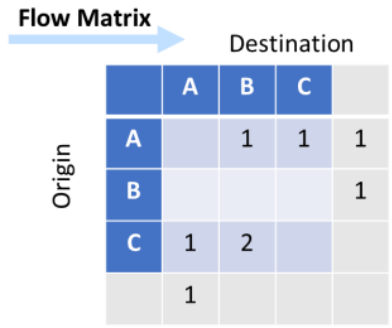

Figure 6. Origin Destination Matrix.

With connected spaces, the internal structure determined by these interfaces connecting one space to another are shown in a matrix, as shown in Figure 6. Any interfaces to outside the system of spaces modelled can also be show, similarly to the common Origin - Destination Matrix (ODM). These same ODM's can be used to show exogenous demand as traffic at the boundaries.

Given the spaces, how they connect, and external demand, the analysis of the systems model requires calculation of estimated traffic and activity as an emergent result of a both a population's demand for movement and services given the supply of these functions within limits. That is, the performance of these spaces given their placiness and pathiness integrated into an smart city + transit hub + transportation network system. 


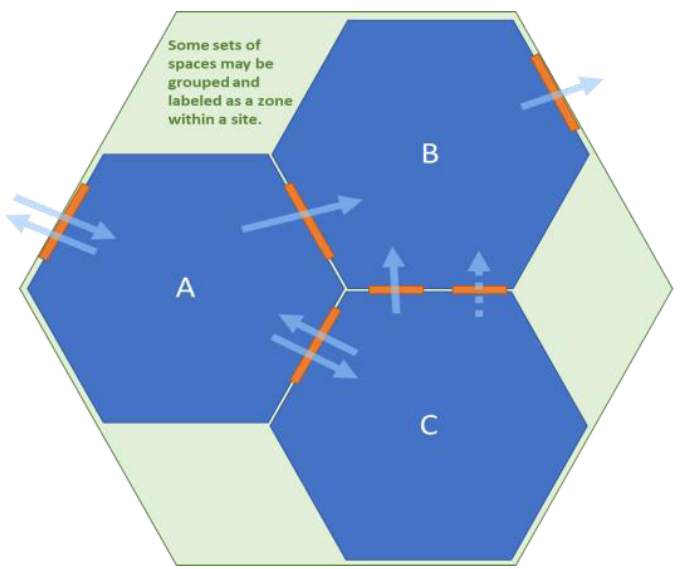

Figure 7. Site model with 3 spaces, 6 interfaces, and 8 flows.

Taken together, the spaces, interfaces, and flows across these interfaces (which may be limited by capacity or certain modes) are combined into a site model. Figure 7 shows a site model with three spaces, six interfaces through which eight flows are indicated. Two of the interfaces and three of the flows are at the boundary of the system.

\section{Case - Japan Rail East Takanawa Gateway}

Japan Rail East (JR-East) is in a strategic transition, having been a traditional (and once national) rail operator to an expanding and private developer of urban spaces, including transportation. An important project for JR-East is the Takanawa Gateway site located near Shinagawa in Tokyo. The site is scheduled to be initially opened for the 2020 Olympics and then redeveloped after as transportation hub and smart city. The Takanawa Gateway project includes approximately 885,000 square meters of developed space beyond the transportation hub.

\subsection{Site and Space models for Takanawa Case}

Our research is underway to treat this site as system as outlined above[15]. Figure 8 below shows a mapping from a set of "architectural" decisions in a morphological matrix to the zones of the Takanawa site. There are three classes of architectural decisions (the rows of the matrix) for the site in this systems model: the functionality of spaces (placiness), the mobility characteristics within each space (pathiness), and the connecting interfaces that lead to an overall site topology.

Figure 9 shows the site model as visualized in our systems modeling platform. The Takanawa Gateway location includes a new train station at the center of an existing rail yard. On the western (lower part of image on left) more than half of the site will be developed across six major zones. The zones stretch from two existing train stations on the main circle rail line in Tokyo: from Tamachi station (on the left in the figure) to Shinagawa station. A site model with 165 spaces defined, 14 distinct functions distributed across these spaces, and 183 interfaces defined for pedestrian access with six availability patterns defined to model functional availability over time. Access from 
offsite defined for every block. The detailed results of this experiment, underway now in collaboration with JR East, will be the subject of our next paper.

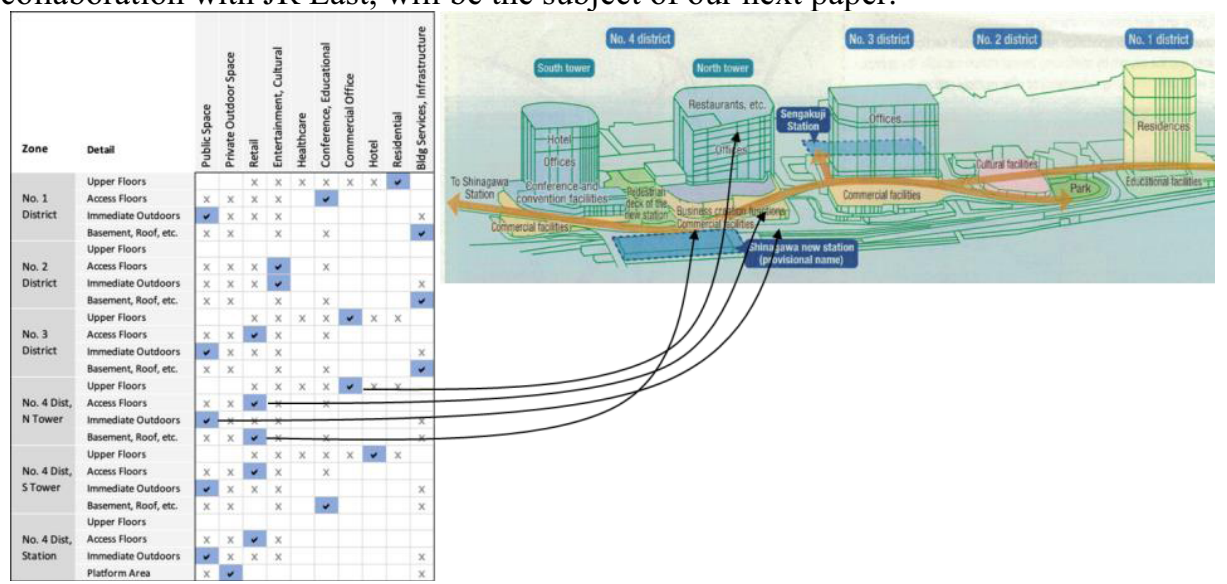

Figure 8. Morphological Matrix for Space Functionality in Takanawa Case [15].
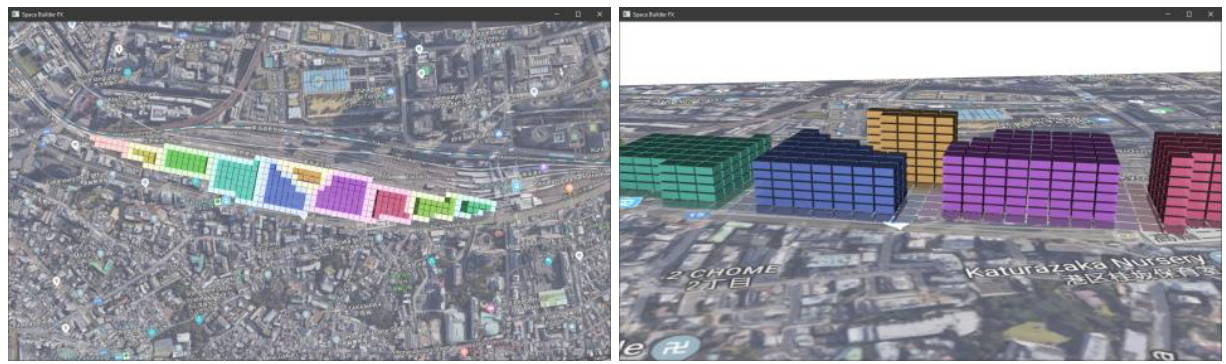

Figure 9. Model Viewer as applied to Takanawa Gateway Case (courtesy Mr. Ira Winder, MIT).

\section{What about Construction?}

After considering this site as a system, with an emphasis on the operational performance, we next asked about the construction of the site. Whereas many of the system models are built to predict performance across the operational life cycle of the system, we ask in this research if key decisions can be evaluated by considering the interplay of site and construction decisions through a systems model.

A key insight for our research team was stimulated by the Paris Rive gauche example, since that site has been in development for 30 years. As such, the construction phase is not separate, but woven into the purpose and performance of the site over time. For those people being transported into the site each day, going to work, moving around the site for various activities, the site performance (both positive and negative) is significant whether during construction or after. Additionally, the stakeholders include those involved and impacted by construction. Therefore, we seek to apply the generalized model of site as system for the construction phase as well.

For construction, the stakeholders, performance of interest, and therefore system architectural decisions will be different. This research proposes a systems model-based 
exploration of implementation options, including decisions regarding phasing and interdependencies between a project's entities, shared facilities during construction, and expected standards, leading to:

- Consideration of more options

- Selection of options to better satisfy stakeholders

- Improved engagement, awareness,

- Improved measures of productivity

- Improved efficiency in the construction process

\subsection{Construction Phase in Site as System}

Due to the complex nature of construction, built facilities are typically divided into components or divided along lines according to function. As construction becomes more complex, and the systems they contain become more integrated, the more necessary it becomes for collaboration across various disciplines to produce feasible, fully functional facilities. Managing a multi-project environment is more than the summation of efforts necessary for a single project, developers that acquire large tracts of land with the purpose of subdividing into separate projects must make a number of decisions over the course of the program, for instance, a developer may choose to develop the entire site at once or in a series of phases completed sequentially or staggered over time.

\subsection{Stakeholder Value Network for Takanawa Case Construction}

What is the role of system architectural decisions related to implementation, such as phasing, construction, and project organization in the project's overall performance? How can the emerging performance be included in the dialogue amongst stakeholders during pre-construction planning of complex, urban infrastructures? Construction is often impacted by, but not in control of emergent outcomes (Figure 10).

\subsection{Emergent System Performance: the Ilities of Construction Implementation:}

The measure of performance of a system are defined as "Ilities, requirements such as flexibility or maintainability, not necessarily part of the fundamental set of functions or constraints"[19].

In contrast to site as system which emphasize operational mobility, economics, and sustainability, the site system including construction may emphasize a broader set of emergent performance measures:

- Efficiency of construction resource utilization

- Occupancy: space function availability and utilization

- Flexibility: capacity to transform by leveraging current features

- Disruption (Space): impediments to non-construction functions and flow, including air/ sound pollution

- Disruption (Construction): congestion and impediments to performance of construction 


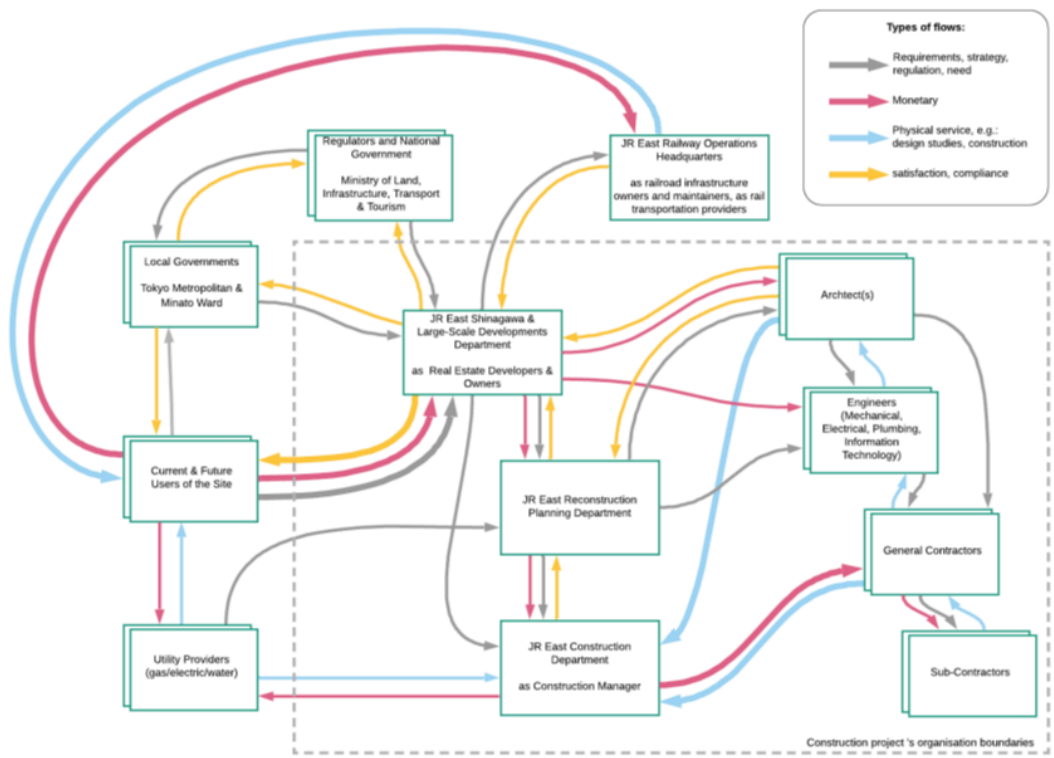

Figure 10. Takanawa Gateway Case: Stakeholder Value Network for Construction.

\subsection{System Architectural Decisions for Construction}

Table 1. Project Level Example Architectural Decisions.

\begin{tabular}{|c|c|c|c|c|}
\hline decision & option 1 & option 2 & option & option 4 \\
\hline Phasing / sequence & $\begin{array}{l}\text { no connection - } \\
\text { set of independent } \\
\text { phases }\end{array}$ & $\begin{array}{l}\text { soft connection - } \\
\text { possible overlap }\end{array}$ & $\begin{array}{l}\text { strong connection } \\
\text { - overlap with } \\
\text { interdependence }\end{array}$ & $\begin{array}{l}\text { total overlap - } \\
\text { strong } \\
\text { interdependence }\end{array}$ \\
\hline $\begin{array}{l}\text { Shared construction } \\
\text { logistic facilities } \\
\text { /services }\end{array}$ & $\begin{array}{l}\text { public } \\
\text { infrastructure } \\
\text { access to site }\end{array}$ & $\begin{array}{l}\text { train or road } \\
\text { access to the site }\end{array}$ & $\begin{array}{l}\text { train or road } \\
\text { access to site and } \\
\text { shared logistic } \\
\text { staging platform }\end{array}$ & $\begin{array}{l}\text { train or road } \\
\text { access, shared } \\
\text { logistic platform } \\
\text { and shared } \\
\text { delivery service }\end{array}$ \\
\hline $\begin{array}{l}\text { Shared construction } \\
\text { offices }\end{array}$ & $\begin{array}{l}\text { do not provide } \\
\text { shared } \\
\text { construction office }\end{array}$ & $\begin{array}{l}\text { shared } \\
\text { construction office } \\
\text { for each phase }\end{array}$ & $\begin{array}{l}\text { provide shared } \\
\text { construction office } \\
\text { for all phases }\end{array}$ & \\
\hline $\begin{array}{l}\text { shared waste } \\
\text { management facilities }\end{array}$ & $\begin{array}{l}\text { no shared waste } \\
\text { management }\end{array}$ & $\begin{array}{l}\text { waste evacuation } \\
\text { from a shared } \\
\text { location }\end{array}$ & $\begin{array}{l}\text { waste collection } \\
\text { and evacuation }\end{array}$ & \\
\hline $\begin{array}{l}\text { Nuisance and } \\
\text { environmental } \\
\text { standards }\end{array}$ & No standards & $\begin{array}{l}\text { free standards - } \\
\text { regulation and free } \\
\text { bottom-up } \\
\text { initiatives }\end{array}$ & $\begin{array}{l}\text { suggest the } \\
\text { standards, provide } \\
\text { incentive }\end{array}$ & $\begin{array}{l}\text { control: set the } \\
\text { standards }\end{array}$ \\
\hline
\end{tabular}




\subsection{System Problem Statement for Construction}

- To include non-expert stakeholders in planning the implementation of a largescale construction development program design

- By allowing early exploration of options for implementation steps, temporary use, and project organization

- Using a generalized system model of construction, transforming the site over time, each having prerequisites, resources, and nominal durations

\subsection{Construction Phase of a Transit Hub when taking a Systems approach}

As this research proceeds, these systems models will be used to explore if a systems design approach can improve performance including improved productivity and reduced long-term construction. Integrating flexibility into the architectural design may be expressed at several levels. The building elements may be selected for durability, ease of installation and later removal, or flexibility for multiple usages if an area has the potential to limit the options for change. The details of the construction process can be optimized for long term reconfigurability of site functions and processes. More difficult to move elements such as utilities and structure may be designed and placed to allow other building elements to be more easily reconfigured. [20]

\subsection{Limitations and Future Work}

This paper describes a generalized modeling approach to assist in high level systems architectural decisions for transit hubs linking the urban neighborhood and regional transportation network. With this model defined several other critical areas need further exploration and definition.

Stakeholder engagement is necessary to create the model and promoted the model viability, accuracy, and usefulness. Methods to ensure that stakeholders successfully engage cannot be limited to field facilitation of meetings but must also include methods to ensure that each stakeholder's unique position and needs are understood by the other stakeholders.

Specific methods to instrument engagement and to quantify the quality of the engagement based on tangible events need to be developed and then tested.[17], [18] This development process will require that both the methods and the test environment are tested against both theoretical and real situations to ensure that the methods remain durable in both typical and exceptional situations.

\section{Acknowledgement}

The authors recognize the support of Japan Rail East, including Mr. Iori Mori for supporting the research. The member of the Global Teamwork Lab (GTL) at MIT and U Tokyo have been very helpful, especially Mr. Ira Winder who developed the visual interface shown in the Takanawa case. 


\section{References}

[1] “Global Construction Outlook to 2022 - Q4 2018 Update,” GlobalData, 4756512, Dec. 2018.

[2] “Commercial Construction Index," USG Corporation and US Chamber of Commerce, Q1 2019.

[3] F. Barbosa et al., Reinventing construction: a route to higher productivity, McKinsey Global Institute, 2017.

[4] M. S. Dobson and D. S. Dobson, Managing Multiple Projects. AMACOM Div American Mgmt Assn, 2011.

[5] B. Flyvbjerg, Over Budget, Over Time, Over and Over Again: Managing Major Projects, in J. K. Pinto, J. Söderlund, and P. W. G. Morris, (eds.) The Oxford Handbook of Project Management, Oxford University Press, Oxford, 2011.

[6] A. Dubois and L.-E. Gadde, The construction industry as a loosely coupled system: implications for productivity and innovation, Construction Management \& Economics, 2002, Vol. 20, no. 7, pp. 621631.

[7] K. I. Gidado, Project complexity: The focal point of construction production planning, Construction Management and Economics, May 1996, Vol. 14, No. 3, pp. 213-225.

[8] K. Sinha and O. L. de Weck, Structural complexity quantification for engineered complex systems and implications on system architecture and design, ASME 2013 International Design Engineering Technical Conferences and Computers and Information in Engineering Conference, 2013, p. V03AT03A044-V03AT03A044.

[9] H. Taguchi, Application of lean enterprise concept to construction firms in Japan, MSc thesis, Massachusetts Institute of Technology, 2004.

[10] M. Wen Feng, M. D. R. Lessard, G. C. Bruce, and E. F. Crawley, Stakeholders, Issues, and the Shaping of Large Engineering Projects, in R.E. Levitt, W. R. Scott and M.J. Garvin (eds.) Public-Private Partnerships for Infrastructure Development: Finance, Stakeholder Alignment, Governance, Edward Elgar Publishing, Northampton, 2013, pp. 87-101.

[11] L. Pelegrin, Teamwork Phenomena: Exploring Path Dependency and Learning in Teams during Architectural Design of Sustainable Maritime Shipping Systems, Master of Science in Engineering and Management, Massachusetts Institute of Technology, Cambridge, MA, USA, 2018.

[12] T. Ishimatsu, O. L. de Weck, J. A. Hoffman, Y. Ohkami, and R. Shishko, Generalized Multicommodity Network Flow Model for the Earth-Moon-Mars Logistics System, Journal of Spacecraft and Rockets, Nov. 2015, Vol. 53, No. 1, pp. 25-38.

[13] E. Crawley, B. Cameron, and D. Selva, System architecture: strategy and product development for complex systems. Prentice Hall Press, Upper Saddle River, 2015.

[14] W. L. Simmons, A framework for decision support in systems architecting, PhD thesis Massachusetts Institute of Technology, 2008.

[15] B.R. Moser, R. de Filippi, and V. Sakhrani, Federated Decision-Making among Networked Stakeholders for Smart Cities, Engineering Project Organization Conference 2019, Vail, Colorado, 25-Jun-2019.

[16] L. Pelegrin, B. Moser, and V. Sakhrani, Exposing Attention-Decision-Learning Cycles in Engineering Project Teams through Collaborative Design Experiments, Proceedings of the 52nd Hawaii International Conference System Sciences, https://scholarspace.manoa.hawaii.edu/handle/10125/59475, Accessed July 8, 2019.

[17] L. Pelegrin, B. Moser, S. Wanaka, M.-A. Chavy-Macdonald, and I. Winder, Field Guide for Interpreting Engineering Team Behavior with Sensor Data, in E. Bonjour, D. Krob, L. Palladino, F. Stephan (eds.) International Conference on Complex Systems Design \& Management, Springer, London, 2018, pp. 203-218.

[18] P. S. Tan and B. R. Moser, Detection of Teamwork Behavior as Meaningful Exploration of Tradespace During Project Design, in E. Bonjour, D. Krob, L. Palladino, F. Stephan (eds.) International Conference on Complex Systems Design \& Management, Springer, London, 2018, pp. 73-87.

[19] T. J. Allen et al., ESD terms and definitions (version 12), Massachusetts Institute of Technology, ESDWP-2002-01, 2001.

[20] A. Siddiqi and O. L. de Weck, Modeling methods and conceptual design principles for reconfigurable systems, Journal of Mechanical Design, 2008, Vol. 130, No. 10, p. 101102. 